Open Access

Journal of Energy and Power Technology

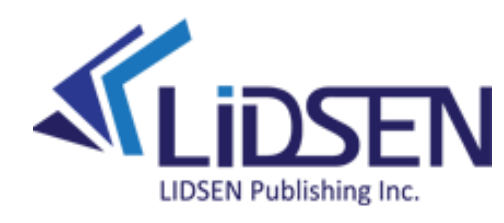

Review

\title{
Accelerated Controller Tuning for Wind Turbines Under Multiple Hazards
}

Aly Mousaad Aly *, Milad Rezaee

Windstorm Impact, Science and Engineering (WISE) Research Lab, Department of Civil and Environment Engineering, Louisiana State University, 3230H Patrick Taylor Hall, Baton Rouge, LA 70803, USA; E-Mails: aly@LSU.edu; mrezae2@lsu.edu

* Correspondence: Aly Mousaad Aly; E-Mail: aly@LSU.edu

Academic Editor: Aritra Ghosh

Special Issue: Progress of Wind Energy Technology and Its Maintenance

Journal of Energy and Power Technology Received: December 26, 2020

2021, volume 3 , issue 1

Accepted: February 19, 2021

doi:10.21926/jept.2101011

Published: March 04, 2021

\begin{abstract}
During their lifecycle, wind turbines can be subjected to multiple hazard loads, such as highintensity wind, earthquake, wave, and mechanical unbalance. Excessive vibrations, due to these loads, can have detrimental effects on energy production, structural lifecycle, and the initial cost of wind turbines. Vibration control by various means, such as passive, active, and semi-active control systems provide crucial solutions to these issues. We developed a novel control theory that enables semi-active controller tuning under the complex structural behavior and inherent system nonlinearity. The proposed theory enables the evaluation of semi-active controllers' performance of multi-degrees-of-freedom systems, without the need for time-consuming simulations. A wide range of controllers can be tested in a fraction of a second, and their parameters can be tuned to achieve system-level performance for different optimization objectives.
\end{abstract}

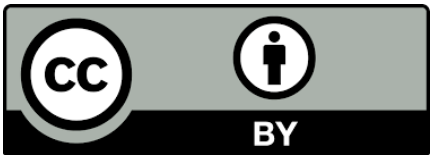

(C) 2021 by the author. This is an open access article distributed under the conditions of the Creative Commons by Attribution License, which permits unrestricted use, distribution, and reproduction in any medium or format, provided the original work is correctly cited. 


\section{Keywords}

Control theory; semi-active control; vibration; wind turbines; multiple hazards; clean energy; smart structures; optimization; damper

\section{Introduction}

The increasing energy consumption and the need for dependable, secure, and clean energy have led to explorations in non-conventional sources, particularly in renewable sources of energy. During the past decade, wind energy has been known as the fastest-growing source of electricity in the world, and it is anticipated to play a significant role in sustainably and powering the future. Today, wind energy has already become one of the main electricity sources in some countries such as Denmark, Portugal, Spain, and Germany, where the contribution of wind energy to the total power is $21 \%, 18 \%, 16 \%$, and $9 \%$, respectively [1]. In 2015, the contribution of wind energy to the nation's electricity in the United States was about $1 \%$, while potentially it could be increased up to $20 \%$, without major changes in the distribution system [2].

Wind turbines can be deployed in coastal zones, inland, and offshore areas, wherever the wind is powerful and uniform, and close enough to the market. However, installing wind turbines in areas with powerful winds and at a short distance to the market can lead to significant design challenges. Modern wind turbines likely face various natural hazards. The population concentration in coastal areas, and the availability of more powerful and uniform wind resources, accelerated the development of coastal and offshore wind farms. However, environmental loads, such as wind and waves are harsher in coastal and offshore areas, which can cause severe damages to wind turbines, or make the produced power more expensive and less dependable.

It has been less than 15 years since wind farms started to be installed in seismic prone areas. Therefore, due to the lack of experience, there is no guaranty that modern wind turbines can survive extreme earthquakes [3]. The effect of pulse-like near-fault ground motions on utility-scale land-based wind turbines was investigated [4]. Flexural testing was conducted on a full-scale 60-kW wind turbine's tower, telescopic steel pipe [5]. The concerns over the possibility of exposure of more modern wind turbines to multi-hazard loads make the understanding of the structural behavior more important than before. These concerns motivated a global endeavor to study and evaluate the performance of modern wind turbines, exposed to various loading scenarios. The efforts are continuing, to provide a comprehensive perspective of the performance and functionality at a system-level, for wind turbines to survive multi-hazard loads.

According to the findings of other researchers, an important trait of modern wind turbines that needs consideration is the flexibility of the structure and the challenge of damping deficit. Consequently, the exposure of a wind turbine to the intense environmental dynamic loads can cause excessive vibrations in the system. The undesirable motion can impose several aftereffects on the wind turbine, such as malfunctioning of mechanical parts in the nacelle or the rotor, power production disorders, reduced wind turbine's availability, crack deployment through the machine, reduced fatigue life of the 
system, increased likelihood of failure, and the need for more frequent maintenance. The direct and indirect consequences of these problems can lead to costly generated electricity.

Despite a limited number of studies on the evaluation and mitigation of wind turbines under multihazard loads, during the past decades, there were ongoing researches and advances in structural dynamic performance improvements of high-rise buildings and tall structures excited by wind and seismic loads [6-11]. It is shown in previous studies that employing external dampers is an effective method to control the vibration of lightly damped, tall, and flexible civil engineering structures $[8,12-$ 16]. However, to design for multi-hazard loads, the aftereffects of applying a specific vibration mitigation method should be seen from a wider perspective. For instance, while vibration isolation is identified as an acceptable approach to increase the damping capacity of a structure under earthquakes, it might not be effective to mitigate wind-induced vibrations. The dynamic response of a base-isolated structure was numerically investigated and optimized for both wind and earthquake [17]. The results showed that base-isolation could not suppress excessive accelerations during high wind events. Similar results are observed from studies that investigated installing the vibration absorbers at the top of a turbine's tower, or the foundation, using semi-active MR dampers $[18,19]$. Implementing an isolation system is beneficial for reducing certain turbine responses, particularly for wind turbines in seismically active regions. In contrast, the hub displacement was increased. The other examples are tuned mass dampers (TMDs) and tuned liquid dampers (TLDs) that more or less have acceptable performance for wind-induced vibrations in wind turbines [10,20-22]. There is no solid agreement, whether or not they are effective enough for reducing ground motion-induced vibrations. TMDs are shown to be effective in wind response control of wind turbines with soil-structure interaction [23]. Some researchers found them ineffective or not significantly effective to mitigate the seismic response [24-26]. Other researchers reported considerable response reduction using TMDs [27-32]. Moreover, having no control over tuning the controller during operation is another important problem of the passive dampers. To tune the passive TMD, comprehensive studies should be done [33], to investigate the performance of the controller under diverse load scenarios and tune the frequency for a specific case. However, the tuning frequency depends on the predefined load scenario and it is not adjustable, which is a drawback for the multi-hazard loading case, where different loading characteristics are expected. In contrast, smart dampers can produce variable control forces, which make them more effective, compared to passive TMDs as reported in various studies [34, 35].

The effectiveness of semi-active and active controllers in mitigating wind-and earthquake-induced vibrations of tall structures was investigated extensively [10, 36-43]. While active dampers show an effective performance to reduce the responses since they inject significant non-dissipative energy to the system and they need external power, employing active dampers to control wind turbines' structural vibration is an imperfect solution due to: (1) the controller can cause instability [44], and (2) the power consumption can be a significant concern in this approach $[45,46]$. However, semi-active dampers showed acceptable performance as they benefit from the positive characteristics of both passive and active controllers. Semi-active dampers do not suffer passive controllers' drawbacks, regarding the frequency tuning, and active controllers' problems, including the need for significant external power resources and instability challenges $[10,11]$. Wind turbines are already installed with power electronic devices, therefore it is convenient to control blade and tower vibrations by the use of 
power electronics-based controllers [47]. The literature has some detailed comparison between passive and semi-active TMDs, in terms of performance, dissipated energy, and TMD stroke $[10,48]$.

An important design task related to the application of controllers to suppress vibrations of a structure is tuning the controller's parameters according to the structure's properties, control objectives, and loading scenarios. In a semi-active damper, the performance of the controller and its success to suppress excessive vibrations depends on the desired control force, as well as the control algorithm that commands the damper. While there are a few recent studies on the advantages of employing semi-active dampers in wind turbines excited by multi-hazard loads $[35,49]$, the evaluation of the controller performance and structural behavior depends on the simulation of several cases with a family of controllers. Therefore, selecting a control approach is not generic and independent of the simulation.

Vibration mitigation through increasing damping can be an effective approach, to remedy these problems. However, vibration mitigation is not a straightforward approach that can be achieved following specific steps for all wind turbines, regardless of their environmental conditions. Since wind turbines may confront unequal natural hazards during their useful life, it should be taken into consideration that each type of natural hazard could have a specific impact on the structure, depending on the overall environmental conditions and structural characteristics. Therefore, it is of utmost importance to assess the structural performance and evaluate the mitigation approaches for various scenarios, to ascertain a proposed solution for one hazard does not make the structure more vulnerable to another hazard. Structural modeling and evaluating the performance of dynamic systems with multidegree-of-freedom is generally a time-consuming process. Evaluating these systems with various control methods makes the models even more tedious and time-consuming. To overcome these issues, an innovative analytical approach is proposed to evaluate the performance of the controlled wind turbines that are modeled as multi-degree-of-freedom systems.

Considering the aforementioned points regarding the effects of multi-hazard loads on wind turbines, and structural control concerns, the current study aimed to address the context of the design of semiactive controllers for wind turbines under multi-hazard loads. This paper employs an energy-based analytical approach to design the controllers for a wind turbine in parked and operating conditions. An outer bracing MR damper system connected to the tower is presented. The control system is identified as an effective option for a wind turbine subjected to seismic and wind loads $[10,50]$. In the next sections, an introduction to wind turbine systems, dynamic modeling, and control will be presented, followed by an application example of a $5 \mathrm{MW}$ wind turbine subjected to wind and earthquake loads. The paper ends with a summary of the main findings.

\section{Wind Turbines}

Wind turbines are devices that harvest the power of the wind and convert it into a useful form of energy (electricity). Wind power makes the blades of a wind turbine turn around a rotor. The main shaft transfers this rotation to the generator via a gearbox unit and the generator converts the mechanical energy to electrical energy. A wind turbine consists of a hub, rotor, blades, nacelle, and tower. Figure 1 illustrates a detailed view of the inside of a wind turbine. The blades and the rotor are rotary parts, 
moving to bypass the wind through the rotor plane. The nacelle is a house for the mechanical parts and the tower is a foundation for the nacelle and the rotor to place them at an appropriate height. The materials that are used to build each component are continually changed and improved over the years, mainly because of significant changes in the height and size of the turbine, to harvest more wind energy by a single unit.

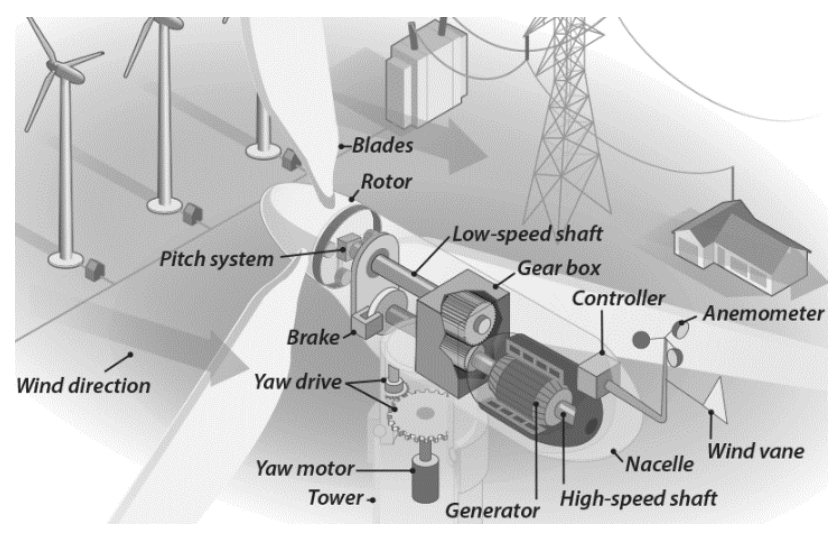

Figure 1 Anatomy of a wind turbine [51].

Developing technology yields increasing wind turbines' efficiency, rotor size, height, and more extracted energy. Developing technology also caused a continuous change in the material used in the construction of wind turbines. The trend is toward lighter weight and low-cost materials, especially for the blades and towers. The tower weight is typically $60 \%$ of the weight of the turbine above the foundation [52]. Therefore, the trend is toward using lighter steel and composite materials. An important issue that should be considered is the material fatigue properties. The majority of the components of a wind turbine, with a useful life of 30 years, are required to be able to sustain $4 \times 10^{8}$ fatigue stress cycles. This is even stricter than the fatigue stress cycles of other man-made structures, such as engines, aircraft, and bridges [52].

The tower can be made of various materials. Steel lattice is the material that was commonly used in early towers. However, because of the exposure of numbers of connections to corrosion, and the sensitivity of weak diagonals to wind excitation, the use of steel lattice towers is not safe to support the modern and higher capacity turbines [53]. Hence, steel lattice was replaced by cylindrical steel tubes in modern towers. Besides, for towers higher than $85 \mathrm{~m}$, concrete can have better performance to balance the vibration excitation, compared to steel tube towers [54]. However, concrete towers may suffer the problem of thermal constraints, leading to cracking, and consequently changing the natural frequency and structural characteristics. The main material used in wind turbines from 2001 to 2010 in the U.S. and worldwide was steel, particularly for large wind turbines [52]. Besides, in coastal areas, the part of fixed wind turbines that are placed in water is normally constructed from concrete.

According to the mentioned points, because the modern wind turbines are taller and lighter than the former generations, these structures are more flexible than before. This flexibility makes them sensitive to the environmental dynamic loads and causes excessive vibrations in the tower as well as the whole structure. Severe vibrations can cause functionality malfunctioning or permanent damages 
to acceleration-sensitive mechanical parts or may reduce the structure's fatigue life and increase the chance of systematic failure.

In a wind turbine, damage can occur everywhere from mechanical and electrical parts to structural parts. However, from a civil engineering point of view, the damages can occur through the foundation, the tower steel tube, bolts, or blades. Structural failures are reported in various countries, such as Scotland, Spain, Germany, Japan, France, Wales, Denmark, and New Zealand [55]. The investigation of wind turbine failures in Germany shows that all mechanical components have almost equal damage frequency as the primary structure [56].

Structural failure has been the third most common industrial accident in wind turbines, with 183 reported instances from the 1970s to 2017 [57]. Storm damage, tower collapse, poor control, lack of maintenance, and component failure were the main concerns in structural failures [57]. Figure 2 shows several structural and blade failures between the 1970s and 2017.

shows the collapse of two wind turbines, due to structural failure in Cape Breton, Canada, and Kansas, U.S. Failure of a wind turbine can have both societal and economic impacts. Modern wind energy harvesting is in a transient stage in most countries from just a potential source of energy to a dominant source of electricity. Condition monitoring and fault detection of wind turbines can improve the reliability of wind turbine power generation $[58,59]$. The failure of wind turbines can make doubt on the reliability of this energy and increase the power production costs. Considering the aforementioned points, and the consequences of failure, it is crucial to study wind turbines from a structural point of view, under dynamic loads, to advance their design.

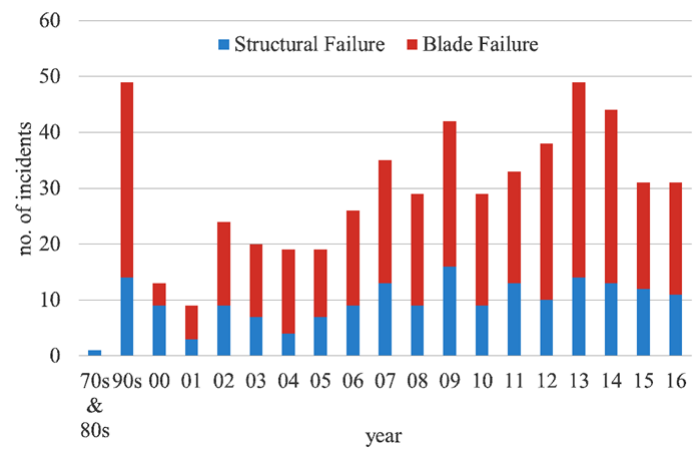

Figure 2 Structural and blade failures between 1970 and 2017.

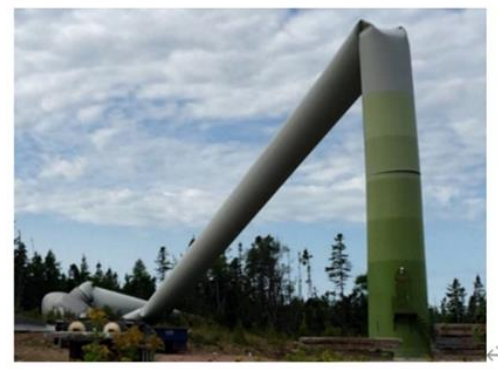

(a)

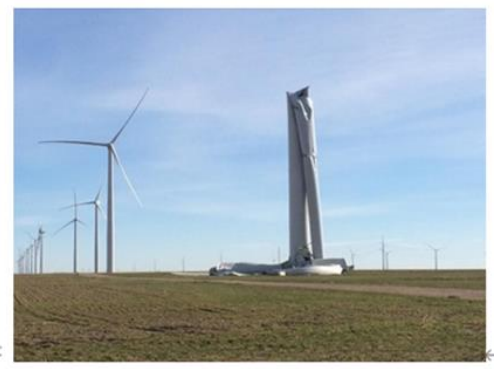

(b)

Figure 3 Wind turbine tower collapse: (a) Cape Breton, Canada [60], and (b) Kansas, USA [61]. 


\section{Structural Dynamics}

Under the action of environmental loads, a wind turbine, as a tall and flexible structure, responds according to the load characteristics and the structure's properties. Like other tall structures, there are several studies on the structural dynamic behavior of wind turbines, particularly by increasing the size of these structures, the static analysis becomes insufficient to design the support structures. As a very basic assumption, a wind turbine can be considered as a spring-dashpot single-degree-of-freedom (SDOF) system excited with a harmonic or random force, or constrained mass at a top of a cantilevered beam [62, 63] (Figure 4). Here, the governing equation of motion for the system can be obtained from Newton's second law as follows.

$$
M \ddot{X}+C \dot{X}+K X=F(t)
$$

Figure 4 Schematic representation of a wind turbine and its simplified equivalent SDOF structural and mechanical spring-dashpot system model.

Where $X$ is the displacement response, $M, C$, and $K$ are the mass, damping coefficient, and stiffness, respectively, and $F$ is the excitation force. The dots on the top of the displacement $(X)$ designate the $1^{\text {st }}$ and $2^{\text {nd }}$ derivatives, representing the velocity and acceleration of the system, respectively. This equation can be rewritten in another form that relates the responses to the damping ratio and the natural frequency of the system:

$$
\ddot{X}+2 \zeta \omega \dot{X}+\omega^{2} X=\frac{1}{M} F(t)
$$

here, $\omega$ and $\zeta$ are the natural frequency and the damping ratio of the system, respectively. As a very basic assumption, the natural frequency, $f_{n 1}$, can be approximated as follows [63].

$$
f_{n 1}^{2}=\frac{3.04}{4 \pi^{2}} \frac{E I}{(M+0.227 \mu L) L^{3}}
$$

$\mu$ is the tower mass per meter, $M$ is the top mass, $E l$ is the tower bending stiffness, and $L$ is the tower height. Considering the nature of the environmental loads on wind turbines, the structure should be designed to have the first natural frequency between the two limits called $1 \mathrm{P}$ and $3 \mathrm{P}$. Where $1 \mathrm{P}$ is a 
rotor loading frequency and $3 \mathrm{P}$ is the blade passing frequency for a three-bladed wind turbine. These frequency limits depend on the type of wind turbine, foundation, and the dominant environmental force. Designing the structure that its natural frequency places somewhere between $\mathrm{PP}$ and $3 \mathrm{P}$ are called a soft-stiff design approach. Here, in this approach, the wind turbine is not that stiff to have a natural frequency higher than $3 \mathrm{P}$ (say $1 \mathrm{~Hz}$ ) and is not as soft as a system with a natural frequency of about $0.17 \mathrm{~Hz}$.

Simplifying a wind turbine as an SDOF system might cause the elimination of considering the real dynamic behavior of the system. Therefore, various studies are carried out on the dynamic of a wind turbine using a modal approach or finite element model that considers the structure as a multi-DOF (MDOF) system. 0 shows an MDOF model of a fixed offshore wind turbine with lumped mass at various heights of the tower in the parked position eliminating the blades-tower coupled interaction. An example of this model is one of the first studies carried out on the effect of wave loads on offshore fixed wind turbines [64]. In this study, a $750 \mathrm{~kW}$ two-bladed wind turbine was modeled as a six DOF system with concentrated masses in the nodes, and the masses were connected with a massless column having finite bending stiffness. Another method that is used in common simulation codes such as CAsT and FAST to find the response of parked or operating wind turbines is modeling based on the solution of the equation of motion for an MDOF beam element for each time step [48, 65-67].

In addition to the simplified models that mainly consider the wind turbine's tower or the wind turbine in the parked position, some models are more sophisticated which take the coupled effects of rotating blades, nacelle, and tower into account (Figure 5). Examples of these models are used in some studies [34, 68-71]. In most of these studies, the equations of motion of the system are developed based on the Euler-Lagrange formulation.

$$
\frac{d}{d t}\left(\frac{\partial T}{\partial \dot{q}_{i}}\right)-\frac{\partial T}{\partial q_{i}}+\frac{\partial V}{\partial q_{i}}=Q_{i}
$$
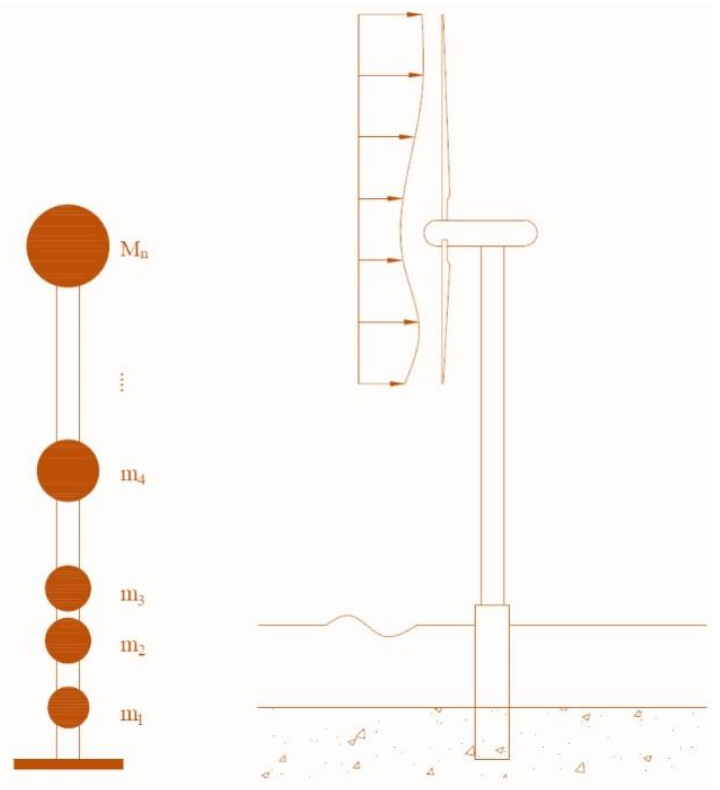

Figure 5 MDOF model of an offshore wind turbine on a mono-pile foundation. 
Here, $T$ is the kinetic energy and $V$ is the potential energy of the system, respectively. $q_{i}$ is the displacement and $Q_{i}$ is the generalized loading corresponding to the $i$-th DOF. Therefore, the mass and stiffness matrices can be obtained by defining appropriate kinetic and potential energy equations. The potential energy term for a wind turbine, considering fore-aft and side-side direction of motion can be written as follows [69]:

$$
\begin{gathered}
\mathrm{V}_{\text {Total }}=\frac{1}{2} \sum_{j=0}^{3} \int_{0}^{L}\left[E I_{\text {in }}(x)\left(\frac{\partial \theta_{i, \text { in }}}{\partial x}\right)^{2} d x+E I_{\text {out }}(x)\left(\frac{\partial \theta_{i, \text { out }}}{\partial x}\right)^{2} d x+2 E I_{\text {inout }}(x)\left(\frac{\partial \theta_{i, \text { in }}}{\partial x}\right)\left(\frac{\partial \theta_{i, \text { out }}}{\partial x}\right) d x\right. \\
\left.+N(x)\left(\frac{\partial u_{i, \text { in }}}{\partial x}\right)^{2} d x+N(x)\left(\frac{\partial u_{i, \text { out }}}{\partial x}\right)^{2} d x+G(x)\left(\frac{\partial u_{i, \text { in }}}{\partial x}\right)^{2} d x+G(x)\left(\frac{\partial u_{i, \text { out }}}{\partial x}\right)^{2} d x\right] \\
+\frac{1}{2} k_{n, \text { in }} \times q_{n, \text { in }}^{2}+\frac{1}{2} k_{n, \text { out }} \times q_{n, \text { out }}^{2}
\end{gathered}
$$

where $L$ and $E$ are the length and the modulus of elasticity of the blade, respectively. $\Omega$ is the rotor's rotational speed. The subscripts in and out are for in and out of rotor plane displacements and $k$ is the stiffness of the tower/nacelle. For an operating wind turbine, the rotation of the blade leads to an excessive centrifugal stiffening effect. The gravity causes additional stiffness in the blades. Therefore, $N(x)$ and $G(x)$ which denotes the centrifugal and gravitational forces can be defined as:

$$
\begin{gathered}
\mathrm{N}(x)=\Omega^{2} \int_{x}^{L} \mu(\xi) \xi d \xi \\
G(x)=-\frac{1}{2} g \cos \Psi_{i} \int_{x}^{L} \mu(\xi) d \xi
\end{gathered}
$$

where variable mass per unit length of the blade is denoted by $\mu(x)$, and $\psi$ is the azimuthal angle of the ith blade because of the rotation. Blades have a $2 \pi / 3$ phase difference.

$$
\Psi_{i}=\Omega \mathrm{t}+\frac{2 \pi}{3}(i-1)
$$

Also, the rotations in in-plane and out-plane are:

$$
\begin{gathered}
\theta_{i, \text { in }}=\frac{\partial u_{i, \text { in }}}{\partial x} \\
\theta_{i, \text { out }}=\frac{\partial u_{i, \text { out }}}{\partial x}
\end{gathered}
$$

the parameters $I_{\text {in }}(x), I_{\text {out }}(x)$, and $I_{\text {inout }}(x)$ represent the in and out of plane second area moments of inertia and the second area products of inertia of the blade's cross-section, respectively. The cross- 
sectional El can be found in NREL documents [72]. Kinetic energy also can be calculated from the following equation:

$$
T_{\text {Nacelle }}=\frac{1}{2} \sum_{i=1}^{3} \int_{0}^{L} \mu(x) v_{i}^{2} d x+\frac{1}{2} M_{n} \dot{q}_{n, \text { in }}^{2}+\frac{1}{2} M_{n} \dot{q}_{n, \text { out }}^{2}
$$

where, $v_{i}$, is the absolute velocity of the ith blade and $\dot{q}$ is absolute in- and out-plane velocity of the nacelle and $M_{n}$ is the mass of the tower [69]. Therefore, the wind turbine's mass, stiffness, and damping matrices can be derived.

Damping is assumed to be stiffness proportional for both the tower and the blades. Therefore, with the damping ratios of $\zeta_{n}$ and $\zeta_{b}$ and natural frequencies of $\omega_{n}$ and $\omega_{b}$ for the nacelle/tower and blades respectively, the damping can be obtained from the following relations:

$$
\begin{aligned}
c_{n} & =2 \frac{\zeta_{n}}{\omega_{n}} K_{n} \\
c_{b} & =2 \frac{\zeta_{b}}{\omega_{b}} K_{b}
\end{aligned}
$$

$K_{n}$ and $K_{b}$ are the stiffness matrices of the nacelle/tower and blades. For more details refer to [68-71].

The presented models consider the structural properties of a wind turbine, regardless of the soilstructure interaction, controlled systems, and applied loads. More details on soil-structure interaction can be found in [69, 73-75]. Having an appropriate wind turbine model provides a tool to investigate the system's responses and its problems. Since the focus of current research is to reduce the excessive vibrations in wind turbines, one should go through the methods to control the structure.

\section{Structural Control}

External dampers can be employed in structures to produce counter forces, reduce the responses, and therefore control structural vibrations. The first important step in the matureness of the application of structural control for civil engineering structures backs to 1994 that the first world conference on structural control was held in Los Angeles [44]. Since 1994, structural controllers are developed to a great extent and various types of them, including passive, semi-active, active, and hybrid controllers are investigated.

\subsection{Passive Control}

Passive control employs tuned devices and there will be no continuous adjustment during the operation. Therefore, there is no need for an external power source and the design concept is much simpler than other types of controllers. Passive dampers can improve the damping ratio of civil engineering structures, which normally are less than $2 \%$. Hence, passive dampers increase the dissipation capacity of the structures. Since the 1990s, impressive efforts have been done to implement 
the theory of applying external dampers into reality as a practical solution for civil engineering structure $[76,77]$.

Tuned mass dampers (TMDs), tuned liquid dampers (TLDs) and viscous fluid dampers are three examples of these controllers that have been used in full-scale civil engineering structures during the last decades. Tuned mass damper conceptually presented by [78]. It consists of a mass connected to the primary mass with a tuned spring and an oil dashpot damping system. The use of these systems is investigated widely for different types of civil engineering structures such as bridges, tall buildings, and wind turbines $[20,21,31,79]$. Two of the tall buildings in the U.S. that are equipped with TMDs are John Hancock Tower in Boston and Citicorp Center in New York [44].

TLDs are similar to TMDs in concept where the motion of the fluid mass generates the counterforce to suppress vibrations of the system. Here, the dimension of the fluid tanker defines the damper's frequency that should be tuned to the natural frequency of the primary structure. Besides, the fluid viscosity and the opening of the barriers inside the tankers can adjust the damping ratio of the controller. Yokohama marine tower and Shin Yokohama are two examples of using TLDs in tall buildings $[44,80]$.

One commonly used class of dampers that employ fluids to dissipate energy is viscous damper (VD) that is widely used in mechanical systems and normally consists of a piston in the damper housing filled with a compound of silicone or oil [81]. Attractive parameters of this class of dampers that are interesting for civil engineering structures include the linear viscous response achieved over a broad frequency range, insensitivity to temperature, and compactness in comparison to stroke and output force [44]. 0 illustrates a typical damper of this type. The movement of the piston through the viscous fluid dissipates energy and if the fluid is purely viscous (e.g. Newtonian), then the damper force is directly proportional to the velocity of the piston [44]. Therefore, it can be modeled as follows:

$$
f_{d}=C_{0} \dot{x}
$$

Figure 6 shows the implementation of viscous fluid dampers in civil engineering applications, via a bracing system, to control the inter-story drift.

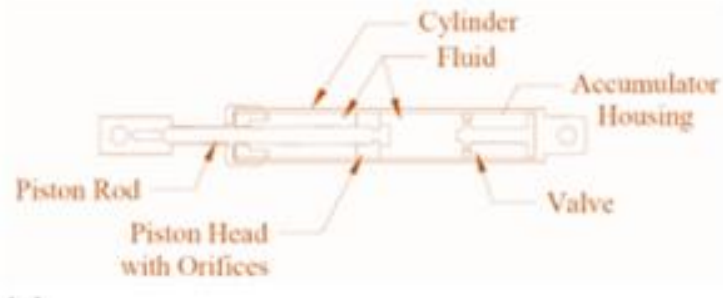

(a)

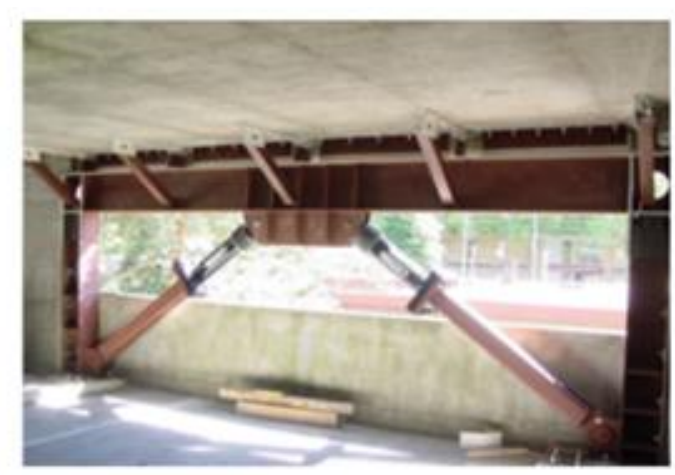

(b)

Figure 6 Fluid viscous dampers: (a) schematic representation from Tylor Devices [82], and (b) large viscous dampers in a building [83]. 


\subsection{Active Control}

In contrary to passive controller devices, active controllers inject energy into the system. These controllers apply force to the structure through actuators and in consequence, adjustments can be made. Due to the real-time changes that the active controllers make in the system, they may lead to instability with the consequences of structural/system failure [44]. Hence, the utmost endeavor should be done to design controllers to improve the dynamic responses of the system instead of making it worse. Considering this fact, different methods and algorithms are developed and various studies are carried out on active controllers. Some of these studies are: sliding mode control [84, 85], saturation control [86, 87], reliability-based control [88-91], fuzzy control [92-94] and neural control [95]. A schematic block diagram of the structural control problem is illustrated in Figure 7. As it is mentioned earlier, an important task is to specify an appropriate control strategy that receives the measured structural responses by sensors, calculate sufficient control signal, and send it to the actuator. So that the actuators improve the structure's performance by injecting enough forces to minimize the errors.

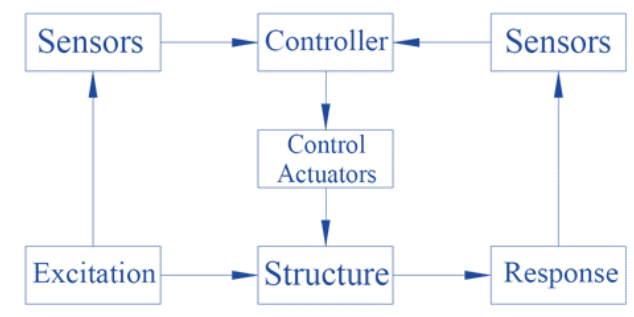

Figure 7 Block diagram of a generic structural control system.

Figure 8 depicts the installation of an active mass damper at the top of a tall building. Here, to control the system, a small mass (about $1 \%$ of the total mass of the system), is connected to the structure through an actuator. Sensors measure responses of the structure. A computer processes the data and according to the control algorithm, it sends appropriate signals to the amplifiers, which finally cause the reaction of the actuators to the excitation. The first full-scale installation of active control in a tall building was in the Kyobashi Center building in 1989. The installed control system consists of two AMDs, one to control transverse motion and the secondary AMD designed to reduce torsional motion [96]. For the list of civil engineering structures that employed external dampers refer to [96].

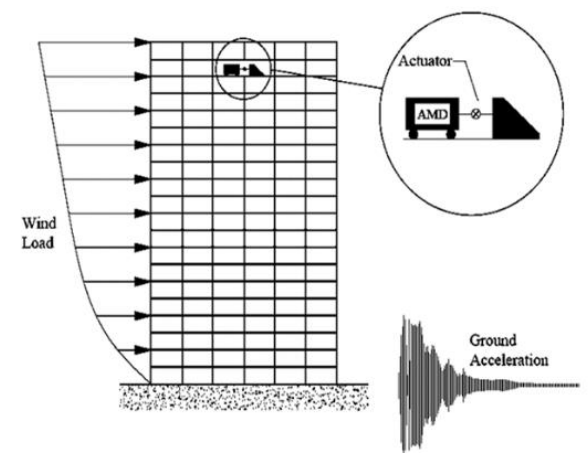

Figure 8 An active mass damper on top of a tall building [97]. 


\subsection{Hybrid Control}

Hybrid controllers are those that are a combination of active, semi-active, and passive dampers. An example of these systems is the structures that are equipped with various viscoelastic dampers and benefit from active base isolation, or active mass dampers [19]. In a hybrid control scheme, an active control may be used to enhance the performance of a passive control scheme. Alternatively, a passive control system can be employed in an active control scheme to reduce the required power [44].

\subsection{Semi-Active Control}

Semi-active dampers are bounded with active and passive dampers. These types of systems do not inject mechanical or non-dissipative energy into the system. Therefore, they can be considered as passive controllers that can be turned on to change the properties of the damper whenever it is desired. Control strategies based on semi-active devices benefit the best features of both passive and active control systems and is receiving the attention of the engineers and scientists as a practical, optimal solution to protect civil engineering structural systems against earthquake and wind loading [44]. Semiactive dampers can mimic the active controller without requiring the associated large power sources. For instance, magnetorheological dampers require only 20-50 watts of power and can operate just on battery power. This is super critical and beneficial during seismic or hurricane events when the main power source to the structure may fail. Besides, for a wind turbine, which is a power generator plant, it would not be beneficial if the control system itself consumes a large amount of power that the turbine generates.

Moreover, because a semi-active controller cannot inject mechanical power into the system, and conceptually is a passive damper with adjustable properties, it does not suffer the instability problems that an active damper can have. Some of the examples of semi-active dampers are variable-orifice fluid dampers and controllable fluid dampers.

\subsection{Variable-Orifice Dampers}

In these types of dampers, the electromechanical, variable-orifice valve controls the opening of the fluid passage and so the hydraulic head loss in the cylindrical piston. This simply translates to altering the fluid resistance or the property of the damper with a very low amount of power. Figure 9 shows a schematic representation of such a device. Some studies implemented such deva ice to control different types of civil engineering structures [98, 99].

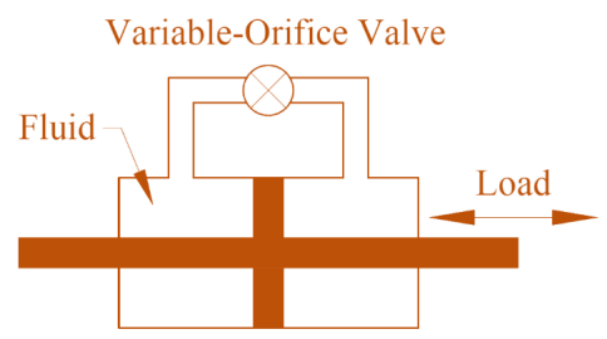

Figure 9 Variable-orifice damper [44]. 


\subsection{Controllable Fluid Damper}

Since controllable valve dampers have various moving mechanical parts, they potentially have malfunctioning probability and maintenance issues, which can reduce their reliability. Controllable fluid dampers are those that the property of the fluid can be changed by electrical (for electrorheological or ER fluids) or magnetic field (for magnetorheological or MR fluids). Hence, since there are no moving parts other than the piston, ER and MR dampers are very reliable. Moreover, they can respond to the changes in milliseconds, so that they decrease the delay considerably, which is significantly important in high-frequency events.

$M R / E R$ free-flowing, linear viscous fluid properties can be changed with controllable yield strength, to a semisolid by exposing to an electric/magnetic field, almost immediately. Typically, MR fluid dampers that have received more interest rather than ER fluid dampers are consist of magnetically polarizable micron-sized particles dispersed in a carrier medium such as mineral or silicone oil. Applying a magnetic field, then forms particle chains in the fluid. Hence, the fluid becomes semisolid with viscoplastic behavior [44]. See [19, 36, 42, 100-102] for more information on the application of these types of dampers in civil engineering structures and wind turbines.

\section{MR Dampers}

To predict and simulate the behavior of an MR damper, an appropriate model should be developed and validated experimentally. In the literature, several conceptual mechanical models are presented by different mathematical expressions. Effective control models of MR dampers are those that precisely can reproduce the nonlinear behavior of the system altered by a magnetic field. According to Sahin et al. (2012) [103], there are two main categories of models: (i) non-parametric, and (ii) parametric models. In non-parametric models, the characteristics of the model are not necessarily physical parameters such as neural networks-based models [104, 105], neuro-fuzzy-based models [106], and Chebyshev polynomials $[107,108]$. Parametric models are those that consist of a set of mechanical elements such as springs, friction, and viscous dampers with various configurations. Therefore, the parameters of this category of models have the physical meaning which makes these types of models more desirable [103]. Brief information on some of the parametric models is presented as follows, including the formulations that are commonly used with these models.

\subsection{Bingham Model}

A simplified mechanical scheme of this model is shown in Figure 10-(a). A viscous damper is set parallel to a Coulomb friction element and the control force is given as follows:

$$
F_{M R}=f_{c} \operatorname{sgn}(\dot{x})+c_{0} \dot{x}+f_{0}
$$


(a)

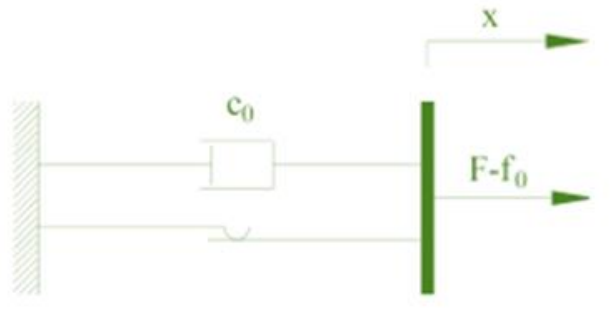

(b)

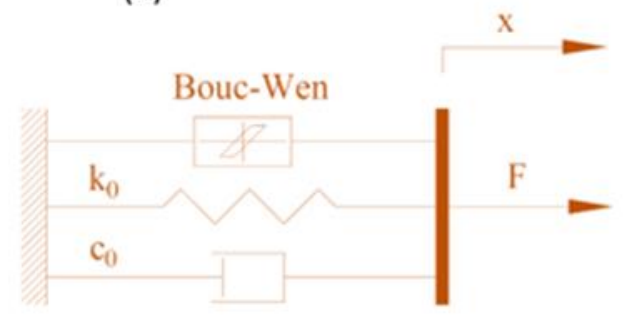

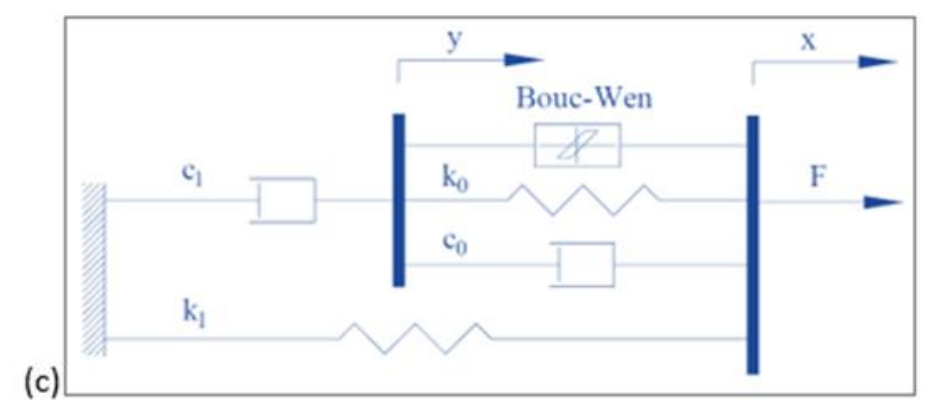

Figure 10 Mechanical modeling of the MR damper: (a) Bingham model, (b) Bouc-Wen model, and (c) modified Bouc-Wen model [109].

where, $c_{0}, f_{0}$, and $f_{c}$ are damping coefficient, force offset, and frictional force related to the fluid yield stress a detailed information can be found in $[109,110]$.

\subsection{Bouc-Wen Model}

As one of the earliest models, the Bouc-Wen model is used widely to model the dynamic behavior of MR dampers. A schematic simplified mechanical representation of this model is shown in Figure 10(b). The control force of the MR damper according to this model can be calculated from the following equation:

$$
F_{M R}=c_{0} \dot{x}+k_{0}\left(x-x_{0}\right)+\alpha z
$$

here, $z$ is defined as:

$$
\dot{z}=-\gamma|\dot{x}| z|z|^{n-1}-\beta \dot{x}|z|^{n}+A \dot{x}
$$

To account for the unloading linearity and pre-yield to post-yield transmission, one can adjust the parameters $\gamma, 6$, and $A[8,109,111]$.

\subsection{Modified Bouc-Wen Model}

In both Bingham and Bouc-Wen models, the force-velocity response does not roll-off when the velocity has a small magnitude and the acceleration and velocity have opposite signs [109]. The modified version of the Bouc-Wen model can better predict the damper force in the region of small 
velocity with the opposite sign of acceleration and velocity. The mechanical scheme of the model is shown in Figure 10-(c), and the force can be calculated using the following formulations.

$$
\begin{gathered}
F_{M R}=c_{1} \dot{y}+k_{1}\left(x-x_{0}\right) \\
\dot{y}=\frac{1}{\left(c_{0}+c_{1}\right)}\left\{\alpha z+c_{0} \dot{x}+k_{0}(x-y)\right\} \\
\dot{z}=-\gamma|\dot{x}-y| z|z|^{n-1}-\beta(\dot{x}-\dot{y})|z|^{n}+A(\dot{x}-\dot{y})
\end{gathered}
$$

To find the parameters in this model for a 20 ton MR damper refer to [100] and for a 1.5 ton MR damper refer to [37]. There are some other models such as the Dahl model, Kwok model, and Gamota and Filisko (1991) that for more information you can refer to [103, 109].

\subsection{Control Algorithms}

During the past decade, significant development has been achieved in the field of active and semiactive controllers in civil engineering structures and various control algorithms are developed. Some of these control algorithms and strategies are based on applying direct velocity feedback (DVFB) control, $\mathrm{H}_{\infty}$ feedback control, wavelet function, fuzzy logic, genetic algorithms (GA), neural networks (NN), linear quadratic regulator (LQR), and linear Gaussian regulator (LGR) [94, 112-115].

One challenge in the use of semi-active technology is the nonlinear nature of these systems. The nonlinearity requires control algorithms that are appropriate for implementation in full-scale structures. Various control algorithms are presented for the semi-active systems, including the skyhook damper control algorithm [116], the bang-bang controller [98], Lyapunov stability theory [117], modulated homogeneous friction algorithm [118], and clipped-optimal controllers [36, 38, 39].

The clipped-optimal controller is known as one of the most common algorithms. According to this algorithm, the linear optimal controller gains, $\mathbf{K}_{c}(s)$, should be designed to calculate the desired control force, $f_{c}$ according to the measured structural responses, $y$, and the measured force, $f$ applied to the system [119]:

$$
f_{c}=\mathcal{L}^{-1}\left\{-\boldsymbol{K}_{c}(s) \mathcal{L}\left\{\begin{array}{l}
\boldsymbol{y}_{\boldsymbol{y}} \\
f
\end{array}\right\}\right\}
$$

and the control law is:

$$
v=V_{\max } H\left(\left\{f_{c}-f\right\} f\right)
$$

A comparison study on the performance of different control algorithms for a three-story building excited with the south-north direction of the El-Centro earthquake showed that the largest reduction in inter-story displacement and the third-floor displacement was achieved with the clipped-optimal algorithm [119]. However, the study shows that the maximum reduction in peak acceleration was obtained by applying the bang-bang approach [119]. The same comparison has been done in a three- 
story building excited with El-Centro earthquake and controlled by various controller strategies, including Passive-off and on, Lyapunov, Decentralized bang-bang, Quasi-bang-bang, Maximum energy dissipation, Modulated homogenous friction, Clipped-optimal, and new quasi-bang-bang controller gives weight to the output in a way that is similar to a fuzzy logic controller [102]. The results revealed that the Lyapunov controller, quasi-bang-bang controller, and clipped-optimal control algorithm provided significant maximum displacement. Also, the clipped-optimal control algorithm gave a good reduction in the maximum absolute accelerations [102]. More information on the control algorithms is provided in the literature $[101,119,120]$.

\section{Controller Design}

In passive dampers, the system tuning includes setting the damping ratio and the frequency ratio once, without further adjustment during the operation. There are some studies on optimized passive damper parameters for wind and earthquake [21, 121-124]. The design procedure for semi-active controllers is more complicated. The performance of the controller depends on the selected algorithm that commands the damper. Moreover, the success of the controller to suppress excessive vibrations effectively depends on the desired control force as well as the control algorithm. Available methods to set the desired control force, and therefore design the optimal controller are based on the simulation. This makes existing methods to be very time-consuming and requires significant computational resources. An alternative to the common simulation-based methods is an energy-based probabilistic approach [125] for SDOF systems. In this approach, the probability of dissipativity of the controller is calculated by solving the Lyapunov function and substituting the results into a stochastic dissipativity index presented by [112]. Then the probability of dissipativity can be applied in an energy-based method to obtain the desired control force without the simulation [112].

Although there are several studies on the control of wind turbines for structural performance improvement, there are just limited studies on the evaluation of the performance of wind turbines for multihazard loads and mitigation of excessive vibrations. Looking into the responses of the structure for various loading scenarios and control approaches is an important task because various excitation sources (e.g. wind, wave, earthquake, rotor imbalance, etc.) affect the structure differently and the controllers might improve a specific response by scarifying the other. To prevent that we need to investigate the performance of the system for multihazard.

In the literature, various control methods, including passive, semi-active and active dampers installed in the nacelle, tower, or the foundation of the turbine are proposed and compared for wind and wave, or wind, and earthquake. For instance, the idea of installing vibration isolators for wind turbines is suggested in different studies. It is proposed to install vibration isolators at the top of the turbine's tower, or at the foundation using semi-active MR dampers to reduce the challenges regards the conventional base isolators for wind turbines $[18,19]$. Both wind and seismic loads are placed on the structure as disturbance forces and the responses are quantified. The results showed that implementing an isolation system was beneficial for reducing certain key parameters of the turbine's structural response, particularly for the wind turbines in seismically active regions. 
Offshore and coastal wind turbines' vibration mitigation is also investigated through different numerical studies considering different types of floating and fixed foundations under the action of wind and wave. In a study that aimed to compare the effects of passive and active tuned mass dampers on a floating wind turbine, a reduction in fatigue loads of the tower base was compared [66]. However, the stroke of the active damper was much greater than the passive damper. This can be a limitation as the available space in the nacelle or at the top of the wind turbine is limited and it is mainly occupied by mechanical parts.

The impacts of pendulum-type passive and semi-active dampers at the top of both floating and fixed offshore wind turbines are also investigated for parked and operating wind turbines [48]. The TMD's oscillations absorbed the energy of tower fore-aft and side-to-side motion, simultaneously. However, since the semi-active TMD (SATMD) was activated around $32 \%$ of the time in the fore-aft direction and $31 \%$ in the side-to-side direction, the power source of the system was increased meaningfully [48]. The performance of TLCD for wind and wave loading on an offshore wind turbine was modeled [62]. The results showed that, while there was a significant reduction in displacement and acceleration at the top of the tower and base shear stress for parked and operating conditions, the reductions meaningfully depended on the wind-wave loads' properties, and in some of the cases, the TLCD even increased the responses.

In a recent study on the control of fixed offshore wind turbines, multihazard loading on wind turbines including wind, wave, and earthquake is evaluated [35]. A SATMD is installed in the nacelle of a wind turbine to control the along-wind displacement of the nacelle/tower and it is shown that the SATMD was more effective than a passive damper to reduce the resonance responses. However, it is not shown that the controller was designed effectively for multihazard.

\section{Advanced Control Theory to Accelerate the Optimal Tuning of Smart Structures}

The Windstorm Impact, Science and Engineering (WISE) research team at Louisiana State University (LSU) devoted efforts to developing advanced control theory to accelerate the optimal tuning of smart structures, to develop novel probabilistic analytical methods to address the complex behavior and inherent nonlinearity in semi-active control, for multiple hazards. The LSU WISE research group developed novel control methods that enabled semi-active controller tuning under complex behavior and inherent nonlinearity, without simulations [50]. The recently developed control theory enables the evaluation of semi-active controllers' performance of multi-degrees-of-freedom systems, without significant computational effort [126]. With this analytical probabilistic control theory, a wide range of controllers can be evaluated in a fraction of a second while optimum control parameters can be tuned to achieve different control objectives. The potential applications include semi-active vibration control in flexible structures under multiple hazard loads brought by wind, wave, and earthquakes.

In the dynamics of structures under multiple hazards, vibration control offers attractive means for protecting structures and inhabitants, as well as balancing between resilience and sustainability. A fundamental task related to the design of semi-active controllers to attenuate structural vibrations is the tuning of the parameters based on the physical properties (mass, stiffness, and damping), mitigation objectives, nature of excitation, etc. Besides, in smart damping, the performance of the 
system to mitigate excessive vibrations is governed by the corresponding ideal active control force, and the algorithm alerting the damping characteristics of the device.

While there are several studies on the advantages of employing semi-active dampers to attenuate vibrations in flexible structures, the controller tuning process is mainly based on numerical simulations, hindering the consideration of different families of controllers, to achieve controller tuning-based performance under varying loading patterns, for instance, excitation due to multiple hazards. To address this challenge, the LSU WISE research team developed a novel control theory that enables the semi-active controller tuning, of multi-degrees-of-freedom systems, under complex behavior and inherent nonlinearity, without simulations [50]. According to the dissipative probability of the corresponding active control forces, a new concept of semi-active control gains was developed:

$$
\begin{aligned}
& k_{s, i}=\frac{1}{2} G_{1, i}\left\{1+\sin ^{2}[\pi(P-0.5)]\right\} \quad \text { and } \quad i=1,2, \ldots, m \\
& \boldsymbol{k}_{s}=\operatorname{diag}\left(k_{s, i}\right) \\
& \omega_{a}=\sqrt{\operatorname{eig}\left(M^{*-1}\left(\mathrm{~K}_{m, a}\right)\right)} ; \mathrm{K}_{m, a}=\mathrm{K}^{*}+\operatorname{diag}\left(\Phi G_{1}\right) \\
& \omega_{s}=\sqrt{\operatorname{eig}\left(M^{*-1}\left(\mathrm{~K}^{*}+\mathrm{k}_{s}\right)\right)} \\
& C_{s 1, i}=\frac{\left|G_{1, i}\right|}{\pi \omega_{s, i}}\left\{1+\sin ^{2}[\pi(P-0.5)]\right\} \text { and } i=1,2, \ldots, m \\
& C_{s 2, i}=\frac{G_{2, i} \omega_{a, i}}{\pi \omega_{s, i}} \times \\
& \left\{\frac{\pi}{2}+\left[\sin [\pi(P-0.5)] \times \sqrt{1-\sin ^{2}[\pi(P-0.5)]}+\tan ^{-1}\left(\frac{\sin [\pi(P-0.5)]}{\sqrt{1-\sin ^{2}[\pi(P-0.5)]}}\right)\right]\right\} \\
& \mathbf{c}_{s}=\operatorname{diag}\left(c_{s 1, i}+c_{s 2, i}\right) \text { and } i=1,2, \ldots, m
\end{aligned}
$$

where $P$ is the dissipative probability of the corresponding optimal active control forces, $G_{1}$ and $G_{2}$ are the active gains, and $\mathrm{K}^{*}$ is the generalized stiffness of the primary structure [50].

With this new theory, a family of controllers can be studied, and their performance can be evaluated in a fraction of a second. This enables controller tuning to achieve optimum parameters for different design objectives. The potential applications of this control theory include vibration control in flexible structures under multiple hazard loads brought by, for example, wind, wave, and seismic loadings. To show the potentiality of the new theory, we considered semi-active controller design in both onshore and offshore wind turbines, in parked and operating positions, under wind, wave, and earthquake external forces, in addition to mechanical unbalance [50]. 


\section{Application Example}

A 5-MW NREL wind turbine is excited by multi-hazard loads (wind and earthquake). The Lagrangian approach was employed to model the wind turbine considering the blade/tower coupling. A control system was investigated: an outer bracing with magnetorheological (MR) dampers (Figure 11) [50, 10]. The outer bracing system benefits a lever mechanism (Figure 11). The lever mechanism magnifies the control force transferred to the structure, which also compensates for the control force reduction due to its connection to the lower part of the tower, instead of the nacelle. The magnification factor is considered as 3.0, and the angle of attachment of the bracing member to the support is chosen as $\theta=$ 45 degrees [41].

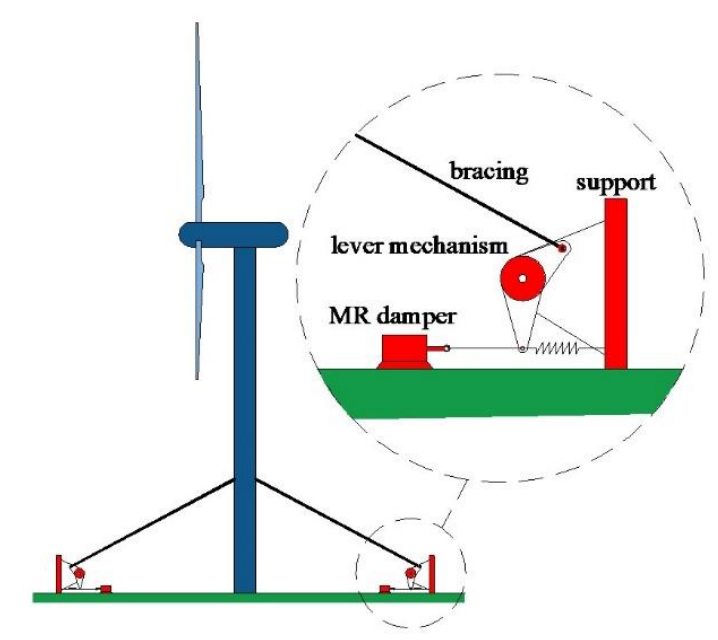

Figure 11 Modeling and control of a 5MW wind turbine: external bracing with magnetorheological (MR) dampers benefiting a lever mechanism to enhance the performance, and lumped mass model [127].

Since the probability of occurrence of both storm and earthquake events at the same time is too low, the occurrence of both was not considered. Instead, earthquake effects are evaluated for the structure equipped with the controller in operating conditions, which is more probable. Hence, the wind speed has a velocity of $25 \mathrm{~m} / \mathrm{s}$ and $12 \%$ turbulence intensity, the seismic excitation was simulated according to the El Centro 1940 earthquake. The outer bracing-damper system was designed and tuned based on the new analytical method (proposed control theory).

\subsection{Controller Tuning}

The new control theory was employed to accelerate the tuning of the semi-active controllers subjected to multiple hazards (Figure 12). A set of two large-scale MR dampers are employed and the force-time history, force-displacement, and force-velocity relationships for the MR damper in two extreme cases of passive-on and passive-off were obtained [50]. The simulated excitation to verify the model was a $1.0 \mathrm{~Hz}$ sinusoidal displacement with an amplitude of $1.27 \mathrm{~cm}$. Simulated control forcetime, force-displacement, and force-velocity are similar to those obtained experimentally in [37]. 


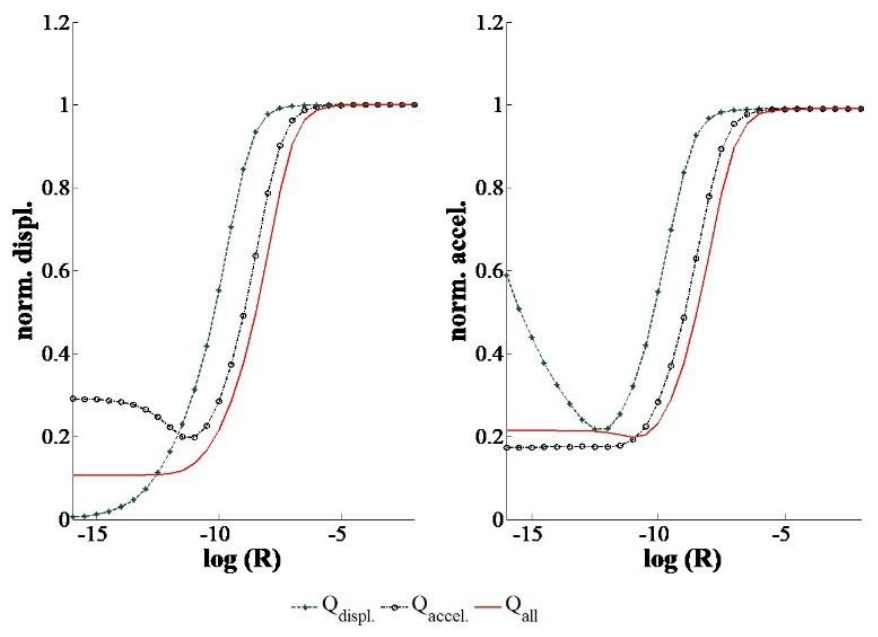

Figure 12 Results obtained by the proposed semi-active controller tuning theory: effect of weighting the $\mathrm{Q}$ and $\mathrm{R}$ matrices to achieve desired control forces for certain optimization objectives - minimizing normalized root-mean-square (RMS) displacement ( $\left.Q_{\text {displ. }}\right)$ and acceleration ( $\left.Q_{\text {accel. }}\right)$, as well as displacement and acceleration, simultaneously $\left(Q_{\text {all. }}\right)$.

Again, three control strategies of passive-on, passive-off, and clipped-optimal were considered. To achieve the optimum $Q$ and $R$ matrices in the LQR method, which yields the desired control force, the analytical method was applied for various controllers to control the first mode of the structure. Thus, four different approaches were defined for the weighting of the $Q$ matrix. The normalized RMS of the responses for all the controller scenarios plotted versus $R$ (Figure 12). The normalization for the displacement and acceleration is done by dividing the controlled responses by the corresponding uncontrolled responses.

The control force normalized over the weight of the lumped mass at the top of the tower. As was expected, the results obtained by the proposed semi-active controller tuning theory show that although weighting displacement, decreased the displacement, however, for more aggressive controllers the damper that was designed based on weighting displacement made the system stiffer, and therefore the acceleration responses increased.

The same issue was observed for weighting velocity. On the other hand, weighting acceleration provided appropriate responses for both acceleration and displacement for $\log (\mathrm{R})=-11$. Also, comparing the performance of $Q_{a l l}$ and $Q_{a c c}$ shows that to achieve a specific reduction in the acceleration, both scenarios required almost the same control force.

\subsection{Parked Onshore Wind Turbine}

Passive-on and passive-off controllers also were examined and compared with the clipped-optimal strategy. The results are presented in Table 1. It is shown that the clipped-optimal controller exhibits the best performance in reducing both acceleration and displacement peaks. Passive-off is slightly better than clipped-optimal just in RMS of the acceleration. For the passive-on case, the MR damper's current is always at its maximum value, and for the passive-off case, it is always zero. The lever mechanism helps improve the performance of the dampers, leading to lower damping capacity or 
reduced number of devices. Nevertheless, the control force in the bracing system will be increased that yields the need for a stronger bracing link [42].

Table 1 Reduction in responses of the nacelle for a parked onshore wind turbine controlled with an outer bracing system.

\begin{tabular}{llllllll}
\hline \multicolumn{8}{c}{ percentage of reduction (controlled/uncontrolled) } \\
\hline & peak to peak & peak to peak & peak displ. & peak acc. & RMS displ. & RMS \\
control strategy & displ. (\%) & accel. (\%) & $(\%)$ & $(\%)$ & (\%) & $(\%)$ \\
passive-off & 92.14 & 93.05 & 82.43 & 80.54 & 62.68 & 89.56 \\
passive-on & 96.70 & 98.23 & 93.56 & 92.10 & 58.20 & 79.64 \\
clipped-optimal & 98.18 & 97.80 & 95.49 & 93.13 & 63.52 & 86.03 \\
\hline
\end{tabular}

\subsection{Operating Onshore Wind Turbine}

The performance of the MR damper to control the wind turbine undergoes operational and seismic loads were evaluated. The time history of the nacelle's responses is shown in Figure 13. It can be seen that the effect of the first shock of the ground acceleration was removed very fast (in less than $30 \mathrm{sec}$.). Also, the vibrations produced by the operational load were almost disappeared. A notable point is that the controller was available from the first seconds of the shock, which is an important aspect of the controller system particularly when the disturbance is the ground acceleration. Because, if there would be a delay in responding to the vibration, the structure may fail even before the controller start to react and reduce the responses. The comparison between applying controller with passive-on, passive-off, and clipped-optimal controller is presented in Table 2. It is shown that applying a clipped-optimal strategy reduced the peaks greater than other controllers did, but the RMS was slightly better for the passive-on controller.

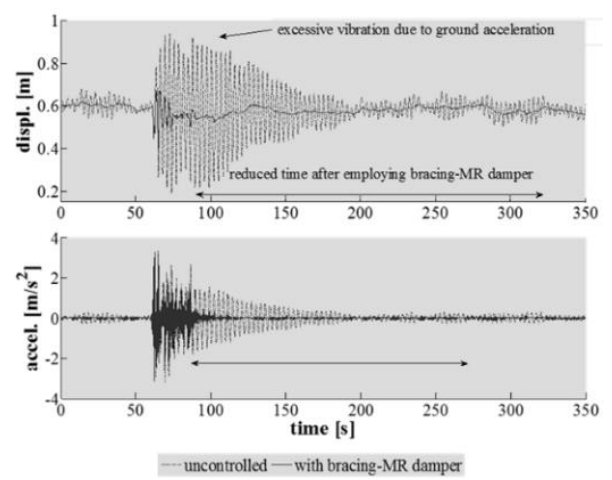

Figure 13 Displacement and acceleration time histories of the nacelle of an operating wind turbine coincident with seismic load: uncontrolled and controlled with the outer bracing system. Results obtained by the proposed semi-active controller tuning theory: time histories of uncontrolled and controlled (employing MR dampers with an outer bracing system) displacement and acceleration responses of the nacelle of an operating wind turbine under earthquake loading (El Centro horizontal component of ground acceleration). 
Table 2 Reduction in responses of the nacelle for an operating onshore wind turbine controlled with the outer bracing system, coincident with an earthquake event.

\begin{tabular}{llllllll}
\hline \multicolumn{7}{c}{ percentage of reduction (controlled/uncontrolled) } \\
\hline & $\begin{array}{l}\text { peak to peak } \\
\text { control strategy }\end{array}$ & displ. (\%) & acc. $(\%)$ & $(\%)$ & $(\%)$ & $(\%)$ & peak \\
passive-off & 81.69 & 81.02 & 40.97 & 2.09 & 61.80 & 39.82 \\
passive-on & 96.91 & 93.49 & 64.78 & 1.79 & 79.22 & 49.82 \\
clipped-optimal & 95.00 & 92.78 & 68.14 & 3.48 & 73.73 & 47.08 \\
\hline
\end{tabular}

The results show that for the operating wind turbine, earthquake excitations lead to excessive vibrations for a long period. However, the properly tuned semiactive damping system improved the performance of the wind turbine by reducing the magnitude and duration of excessive vibrations. For vibration control under multiple hazards, including wind and earthquake, the control system is immediately available, compared to, for instance, the classical slow responding tuned mass damper (Figure 13).

This new control theory reduced the design and performance evaluation time significantly. For instance, the CPU-time required for a single performance evaluation case considering specific weighting matrices, using a $2.5 \mathrm{GHz}$ Intel Core i5-2400S processor PC, was about $3 \mathrm{hrs}$. This amount of time increases significantly for aggressive primary active controllers, which means that several days/weeks are needed to evaluate the performance of a family of controllers under certain loading excisions. This amount of simulation time can increase exponentially when the objective is to design semi-active controllers for multiple hazards, for different optimization objectives - e.g. minimizing displacement, velocity, acceleration, or all responses. The new analytical control theory reduced the total time to a few seconds for a wide range of controllers and optimization objectives.

\section{Summary}

Structural design for multiple hazards is a challenge that requires the adoption and consideration of new control methods, theory, devices, and implementation techniques. Advanced control methods can yield more resilient and sustainable infrastructure, such as wind turbines, as well as other flexible structures, such as high-rise buildings, towers, and long-span bridges under the impact of wind, wave, and seismic excitations. The recently developed semi-active gain theory can be a benchmark for further investigations on structural control in wind turbines and other structures. A vibration mitigation technique with outer bracing using MR dampers is presented. To select the semi-active controller, the generic energy-based probabilistic approach was employed. This analytical approach reduced the time significantly. For an operating wind turbine, an earthquake event caused excessive vibrations for a period much longer than the event itself. The implementation of external dampers not only improved the performance of the system by reducing excessive vibrations but also reduced the duration of excessive vibrations. For vibration control under earthquakes, it is shown that the outer bracing system is immediately available to reduce the response. The time window required to eliminate the effect of 
the earthquake ground acceleration on the operating wind turbine for the outer bracing system was short. Besides, the analytical approach has potential applications in various mechanical systems. The goal is to build new structures and retrofit existing ones in ways that can balance resilience with sustainability, enhance safety, and reduce the huge cost of rebuilding due to multiple hazards. This will broadly impact the wind/structural engineering research field and facilitate effective investments in the infrastructure industry that will result in more resilient and sustainable communities, improve the quality of life, and contribute to economic growth.

\section{Author Contributions}

The authors contributed equally.

\section{Competing Interests}

The authors have declared that no competing interests exist.

\section{References}

1. WWEA. World wind energy report 2011. Bonn, Germany: World Wind Energy Association; 2011.

2. Laks JH, Pao LY, Wright AD. Control of wind turbines: Past, present, and future. Proceedings of 2009 American Control Conference; 2009 June 10-12; St Louis, MO, US. Piscataway: IEEE.

3. Katsanos EI, Thöns S, Georgakis CT. Wind turbines and seismic hazard: A state-of-the-art review. Wind Energy. 2016; 19: 2113-2133.

4. Sigurðsson GÖ, Rupakhety R, Rahimi SE, Olafsson S. Effect of pulse-like near-fault ground motions on utility-scale land-based wind turbines. Bull Earthq Eng. 2020; 18: 953-968.

5. Campione G, Monaco A, Cannella F. Flexural test on a full-scale 60-kw wind turbine-tower telescopic steel pipe. Pract Period Struct Des Constr. 2019; 24: 04019012.

6. Aly $A M, G o l$ Zaroudi $H$, Rezaee M. Hurricane hazard mitigation in traffic light support structures. Final Report. Baton Rouge: Louisiana Transportation Research Center; 2016; FHWA/LA.15/14-2TIRE. Available from: https://www.Itrc.Isu.edu/pdf/2016/14-2TIRE.pdf.

7. Kaloop MR, Hu JW, Bigdeli Y. Identification of the response of a controlled building structure subjected to seismic load by using nonlinear system models. Appl Sci. 2016; 6: 301.

8. Bigdeli Y, Kim D. Damping effects of the passive control devices on structural vibration control: TMD, TLC and TLCD for varying total masses. KSCE J Civ Eng. 2016; 20: 301-308.

9. Bigdeli Y, Kim D. Response control of irregular structures using structure-TLCD coupled system under seismic excitations. KSCE J Civ Eng. 2015; 19: 672-681.

10. Rezaee M, Aly AM. Vibration control in wind turbines for performance enhancement: $A$ comparative study. Wind Struct. 2016; 22: 107-131.

11. Aly AM, Abburu S. On the design of high-rise buildings for multihazard: Fundamental differences between wind and earthquake demand. Shock Vib. 2015; 2015: 148681.

12. Zheng M, Yang ZJ, Yang S, Still B. Modeling and mitigation of excessive dynamic responses of wind turbines founded in warm permafrost. Eng Struct. 2017; 148: 36-46. 
13. Farghaly AA. Seismic analysis of adjacent buildings subjected to double pounding considering soilstructure interaction. Int J Adv Struct Eng. 2017; 9: 51-62.

14. Ramezani M, Bathaei A, Zahrai SM. Designing fuzzy systems for optimal parameters of TMDs to reduce seismic response of tall buildings. Smart Struct Syst. 2017; 20: 61-74.

15. AlHamaydeh M, Jaradat MA, Serry M, Sawaqed L, Hatamleh KS. Structural control of MR-dampers with genetic algorithm-optimized Quasi-Bang-Bang controller. Proceedings of 2017 7th International Conference on Modeling, Simulation, and Applied Optimization (ICMSAO); 2017 April 4-6; Sharjah, UAE. Piscataway: IEEE.

16. Mohammadi RK, Haghighipour F. Implementation of uniform deformation theory in semi-active control of structures using fuzzy controller. Smart Struct Syst. 2017; 19: 351-360.

17. Vulcano A. Comparative study of the earthquake and wind dynamic responses of base-isolated buildings. J Wind Eng Ind Aerodyn. 1998; 74: 751-764.

18. Van der Woude C, Narasimhan S. A study on vibration isolation for wind turbine structures. Eng Struct. 2014; 60: 223-234.

19. Caterino N. Semi-active control of a wind turbine via magnetorheological dampers. J Sound Vib. 2015; 345: 1-17.

20. Murtagh PJ, Ghosh A, Basu B, Broderick BM. Passive control of wind turbine vibrations including blade/tower interaction and rotationally sampled turbulence. Wind Energy. 2008; 11: 305-317.

21. Si Y, Karimi HR, Gao H. Modelling and optimization of a passive structural control design for a spartype floating wind turbine. Eng Struct. 2014; 69: 168-182.

22. Stewart GM, Lackner MA. The impact of passive tuned mass dampers and wind-wave misalignment on offshore wind turbine loads. Eng Struct. 2014; 73: 54-61.

23. Gaur S, Elias S, Höbbel T, Matsagar VA, Thiele K. Tuned mass dampers in wind response control of wind turbine with soil-structure interaction. Soil Dyn Earthq Eng. 2020; 132: 106071.

24. Gupta YP, Chandrasekaran AR. Absorber system for earthquake excitation. Proceedings of the Fourth World Conference on Earthquake Engineering; 1969 January 13th-18th; Santiago, Chile. Santiago: Universidad de Chile. pp.139-148.

25. Kaynia AM, Veneziano D, Biggs JM. Seismic effectiveness of tuned mass dampers. J Struct Div. 1981; 107: 1465-1484.

26. Sladek JR, Klingner RE. Effect of tuned-mass dampers on seismic response. J Struct Eng. 1983; 109: 2004-2009.

27. Wirsching PH, Yao JT. Safety design concepts for seismic structures. Comput Struct. 1973; 3: 809826.

28. Wirsching $\mathrm{PH}$, Campbell GW. Minimal structural response under random excitation using the vibration absorber. Earthq Eng Struct Dyn. 1973; 2: 303-312.

29. Ohno S, Watari A, Sano I. Optimum tuning of the dynamic damper to control response of structures to earthquake ground motion. Proceedings of the Sixth World Conference on Earthquake Engineering; 1977 January 10th-14th; New Delhi, India. Pune: Sarita Prakashan. pp.157-161.

30. Villaverde R. Reduction seismic response with heavily-damped vibration absorbers. Earthq Eng Struct Dyn. 1985; 13: 33-42.

31. Villaverde R. Seismic control of structures with damped resonant appendages. Proc First World Conf 
Struct Control. 1994; 1: 113-122.

32. Villaverde R, Koyama LA. Damped resonant appendages to increase inherent damping in buildings. Earthq Eng Struct Dyn. 1993; 22: 491-507.

33. Dinh VN, Basu B. Passive control of floating offshore wind turbine nacelle and spar vibrations by multiple tuned mass dampers. Struct Control Health Monit. 2015; 22: 152-176.

34. Dinh VN, Basu B, Nagarajaiah S. Semi-active control of vibrations of spar type floating offshore wind turbines. Smart Struct Syst. 2016; 18: 683-705.

35. Sun C. Semi-active control of monopile offshore wind turbines under multi-hazards. Mech Syst Signal Process. 2018; 99: 285-305.

36. Dyke SJ, Spencer Jr BF, Sain MK, Carlson JD. Seismic response reduction using magnetorheological dampers. IFAC Proc Vol. 1996; 29: 5530-5535.

37. Dyke SJ, Spencer Jr BF, Sain MK, Carlson JD. Modeling and control of magnetorheological dampers for seismic response reduction. Smart Mater Struct. 1996; 5: 565-575.

38. Dyke SJ, Spencer Jr BF, Quast P, Kaspari Jr DC, Sain MK. Implementation of an active mass driver using acceleration feedback control. Comput Aided Civ Infrastruct Eng. 1996; 11: 305-323.

39. Dyke SJ, Spencer Jr BF, Quast P, Sain MK, Kaspari Jr DC, Soong TT. Acceleration feedback control of MDOF structures. J Eng Mech. 1996; 122: 907-918.

40. Occhiuzzi A. Additional viscous dampers for civil structures: Analysis of design methods based on effective evaluation of modal damping ratios. Eng Struct. 2009; 31: 1093-1101.

41. Aly AM, Zasso A, Resta F. On the dynamics of a very slender building under winds: Response reduction using MR dampers with lever mechanism. Struct Des Tall Spec Build. 2011; 20: 539-551.

42. Zasso A, Aly AM, Resta F. MR dampers with lever mechanism for response reduction in high-rise buildings under wind loads. Proceedings of 5th European \& African Conference on Wind Engineering; 2009 July 19th-23rd; Florence, Italy. Firenze: Firenze University Press.

43. Sun C, Nagarajaiah S. Study on semi-active tuned mass damper with variable damping and stiffness under seismic excitations. Struct Control Health Monit. 2014; 21: 890-906.

44. Housner G, Bergman LA, Caughey TK, Chassiakos AG, Claus RO, Masri SF, et al. Structural control: Past, present, and future. J Eng Mech. 1997; 123: 897-971.

45. Choi SB, Hong SR, Sung KG, Sohn JW. Optimal control of structural vibrations using a mixed-mode magnetorheological fluid mount. Int J Mech Sci. 2008; 50: 559-568.

46. Weber F. Semi-active vibration absorber based on real-time controlled MR damper. Mech Syst Signal Process. 2014; 46: 272-288.

47. Basu B, Staino A, Basu M. Role of flexible alternating current transmission systems devices in mitigating grid fault-induced vibration of wind turbines. Wind Energy. 2014; 17: 1017-1033.

48. Tsouroukdissian AR, Lackner M, Cross-Whiter J, Park SM, Pourazarm P, Cava W La, et al. Smart novel semi-active tuned mass damper for fixed bottom and floating offshore wind. Proceeding of Offshore Technology Conference; 2016 May 2nd-5th; Houston, Texas, US. Houston: Offshore Technology Conference.

49. Sun C. Mitigation of offshore wind turbine responses under wind and wave loading: Considering soil effects and damage. Struct Control Health Monit. 2018; 25: e2117.

50. Rezaee M, Aly AM. Vibration control in wind turbines to achieve desired system-level performance 
under single and multiple hazard loadings. Struct Control Health Monit. 2018; 25: e2261.

51. Office of Energy Efficiency \& Renewable. The inside of a wind turbine [Internet]. Washington: Department of Energy. Available form: https://www.energy.gov/eere/wind/inside-wind-turbine.

52. Ancona D, McVeigh J. Wind turbine-materials and manufacturing fact sheet [Internet]. Washington: Office of Industrial Technologies, U.S. Department of Energy; 2001. Available from: http://www.perihq.com/documents/WindTurbine-MaterialsandManufacturing FactSheet.pdf.

53. Ciang CC, Lee JR, Bang HJ. Structural health monitoring for a wind turbine system: A review of damage detection methods. Meas Sci Technol. 2008; 19: 122001.

54. Harte R, Van Zijl GP. Structural stability of concrete wind turbines and solar chimney towers exposed to dynamic wind action. J Wind Eng Ind Aerodyn. 2007; 95: 1079-1096.

55. Rosenbloom E. A problem with wind power [Internet]. Available from: http://www.aweo.org/problemwithwind.html.

56. Hahn B, Durstewitz M, Rohrig K. Reliability of Wind Turbines: Experiences of 15 years with 1,500 WTs. Wind Energy. 2007: 329-332.

57. Caithness Windfarm Information Forum 2017. Summary of Wind Turbine Accident data to 31 December 2016. 2017.

58. Hameed Z, Hong YS, Cho YM, Ahn SH, Song CK. Condition monitoring and fault detection of wind turbines and related algorithms: A review. Renew Sustain Energ Rev. 2009; 13: 1-39.

59. Habibi H, Howard I, Simani S. Reliability improvement of wind turbine power generation using model-based fault detection and fault tolerant control: A review. Renew Energ. 2019; 135: 877-896.

60. Brett Ruskin. Wind turbine collapse wreckage in Cape Breton combed for clues of cause [Internet]. Toronto: CBC News; 2016. Available from: https://www.cbc.ca/news/canada/nova-scotia/windturbine-collapse-point-tupper-cape-breton-enercon-renewable-1.3734562.

61. KWCH. Wind turbine collapse in Kansas. 2014.

62. Chen J, Liu Y, BaiX. Shaking table test and numerical analysis of offshore wind turbine tower systems controlled by TLCD. Earthq Eng Eng Vib. 2015; 14: 55-75.

63. van der Tempel J, Molenaar DP. Wind turbine structural dynamics-a review of the principles for modern power generation, onshore and offshore. Wind Eng. 2002; 26: 211-222.

64. Rogers N, Still D. Structural dynamics of offshore wind turbines subject to extreme wave loading. In: European Wind Energy Conference. London: James \& James; 1999.

65. Xu N, Ishihara T. Analytical formulae for wind turbine tower loading in the parked condition by using quasi-steady analysis. Wind Eng. 2014; 38: 291-309.

66. Lackner MA, Rotea MA. Structural control of floating wind turbines. Mechatronics. 2011; 21: 704719.

67. Jonkman JM. Dynamics modeling and loads analysis of an offshore floating wind turbine. Golden, CO: National Renewable Energy Laboratory; 2007; NREL/TP-500-41958.

68. Quilligan A, O'Connor A, Pakrashi V. Fragility analysis of steel and concrete wind turbine towers. Eng Struct. 2012; 36: 270-282.

69. Fitzgerald B, Basu B. Structural control of wind turbines with soil structure interaction included. Eng Struct. 2016; 111: 131-151.

70. Hansen $\mathrm{MH}$. Improved modal dynamics of wind turbines to avoid stall-induced vibrations. Wind 
Energy. 2003; 6: 179-195.

71. Arrigan J, Pakrashi V, Basu B, Nagarajaiah S. Control of flapwise vibrations in wind turbine blades using semi-active tuned mass dampers. Struct Control Health Monit. 2011; 18: 840-851.

72. Jonkman J, Butterfield S, Musial W, Scott G. Definition of a 5-MW reference wind turbine for offshore system development. Golden, CO: National Renewable Energy Laboratory; 2019; NREL/TP500-38060.

73. Abhinav KA, Saha N. Dynamic analysis of an offshore wind turbine including soil effects. Procedia Eng. 2015; 116: 32-39.

74. Harte M, Basu B, Nielsen SR. Dynamic analysis of wind turbines including soil-structure interaction. Eng Struct. 2012; 45: 509-518.

75. Lombardi D, Bhattacharya S, Wood DM. Dynamic soil-structure interaction of monopile supported wind turbines in cohesive soil. Soil Dyn Earthq Eng. 2013; 49: 165-180.

76. Soong TT, Constantinou MC. Passive and active structural vibration control. Cham: Springer International Publishing; 1994.

77. Soong TT, Dargush GF. Passive energy dissipation systems in structural engineering. Chichester: Wiley; 1997.

78. Den Hartog JP. Mechanical vibrations. 3rd ed. New York: McGraw-Hill Book Company; 1947.

79. Lin $\mathrm{YY}$, Cheng $\mathrm{CM}$, Lee $\mathrm{CH}$. A tuned mass damper for suppressing the coupled flexural and torsional buffeting response of long-span bridges. Eng Struct. 2000; 22: 1195-1204.

80. Tamura Y, Fujii K, Ohtsuki T, Wakahara T, Kohsaka R. Effectiveness of tuned liquid dampers under wind excitation. Eng Struct. 1995; 17: 609-621.

81. Makris N, Constantinou MC. Viscous dampers: Testing, modeling and application in vibration and seismic isolation. Buffalo: National Center for Research on Earthquake Engineering; 1990.

82. Constantinou MC, Symans MD, Tsopelas P, Taylor DP. Fluid viscous dampers in applications of seismic energy dissipation and seismic isolation. Proc ATC 17-1 Semin Seism Isol Passiv Energy Dissipation Act Control. 1993; 2: 581-592.

83. Vijayaraja. Passive energy dissipation devices in earthquake resistant buildings [Internet]. 2013. Available from: https://buildcivil.wordpress.com/2013/11/25/passive-energy-dissipation-devices/.

84. Nonami $\mathrm{K}$, Nishimura $\mathrm{H}$, Tian $\mathrm{H}$. $\mathrm{H}^{\infty} / \mu$ control-based frequency-shaped sliding mode control for flexible structures. Am Soc Mech Eng Publications PVP. 1994; 289: 19.

85. Yang JN, Wu JC, Agrawal AK. Sliding mode control for seismically excited linear structures. J Eng Mech. 1995; 121: 1386-1390.

86. Chase JG, Smith HA. Robust $\mathrm{H}_{\infty}$ control considering actuator saturation. I: Theory. J Eng Mech. 1996; 122: 976-983.

87. Agrawal AK, Yang JN, Schmitendorf WE, Jabbari F. Stability of actively controlled structures with actuator saturation. J Struct Eng. 1997; 123: 505-512.

88. Spencer Jr BF, Sain MK, Kantor JC, Montemagno C. Probabilistic stability measures for controlled structures subject to real parameter uncertainties. Smart Mater Struct. 1992; 1: 294.

89. Spencer Jr BF, Sain MK, Won CH, Kaspari DC, Sain PM. Reliability-based measures of structural control robustness. Struct Saf. 1994; 15: 111-129.

90. Field Jr RV, Voulgaris PG, Bergman LA. Methods to compute probabilistic measures of robustness 
for structural systems. J Vib Control. 1996; 2: 447-463.

91. Field Jr RV, Voulgaris PG, Bergman LA. Probabilistic stability robustness of structural systems. J Eng Mech. 1996; 122: 1012-1021.

92. Nagarajaiah S. Fuzzy controller for structures with hybrid isolation system. In Structural Control: Proceedings of the 2nd World Conference on Structural Control. New York: Wiley; 1994.

93. Subramaniam RS, Reinhorn AM, Riley MA, Nagarajaiah S. Hybrid control of structures using fuzzy logic. Compu Aided Civ Infrastruct Eng. 1996; 11: 1-17.

94. Aly AM. Proposed robust tuned mass damper for response mitigation in buildings exposed to multidirectional wind. Struct Des Tall Spec Build. 2014; 23: 664-691.

95. Ghaboussi J, Joghataie A. Active control of structures using neural networks. J Eng Mech. 1995; 121: 555-567.

96. Spencer Jr BF, Nagarajaiah S. State of the art of structural control. J Struct Eng. 2003; 129: 845-856.

97. Spencer BF, Sain MK. Controlling buildings: A new frontier in feedback. IEEE Control Syst. 1997; 17: 19-35.

98. Feng $Q$ and Shinozuka $M$. Use of a variable damper for hybrid control of bridge response under earthquake. Proceedings of the US national workshop on structural control research; 1990 October 25th-26th; Los Angeles, CA, US. Los Angeles: University of Southern California.

99. Kamagata $\mathrm{S}$, Kobori T. Autonomous adaptive control of active variable stiffness system for seismic ground motion. Proceeding of First World Conference on Structural Control; 1994 August 3rd-5th; Los Angeles, CA, USA. Los Angeles: International Association for Structural Control.

100.Spencer BF, Carlson JD, Sain MK, Yang G. On the current status of magnetorheological dampers: Seismic protection of full-scale structures. Proceedings of the 1997 American Control Conference; 1997 June 6th; Albuquerque, NM, USA. Piscataway: Institute of Electrical and Electronics Engineer.

101.Spencer BF, Dyke SJ, Sain MK. Magnetorheological dampers: A new approach to seismic protection of structures. Proceedings of 35th IEEE Conference on Decision and Control; 1996 December 13th; Kobe, Japan. Piscataway: Institute of Electrical and Electronics Engineer.

102. Aly AM. Vibration control of buildings using magnetorheological damper: A new control algorithm. J Eng. 2013; 2013: 596078.

103. Şahin I, Engin T, Çeşmeci Ş. Comparison of some existing parametric models for magnetorheological fluid dampers. Smart Mater Struct. 2010; 19: 035012.

104. Chang CC, Roschke P. Neural network modeling of a magnetorheological damper. J Intell Mater Syst Struct. 1998; 9: 755-764.

105. Chang CC, Zhou L. Neural network emulation of inverse dynamics for a magnetorheological damper. J Struct Eng. 2002; 128: 231-239.

106. Schurter K, Roschke P. Fuzzy modeling of a magnetorheological damper using ANFIS. Proceeding of Ninth IEEE International Conference on Fuzzy Systems; 2020 May 7th-10th; San Antonio, TX, USA. Piscataway: Institute of Electrical and Electronics Engineer.

107. Ehrgott RC, Masri SF. Modeling the oscillatory dynamic behaviour of electrorheological materials in shear. Smart Mater Struct. 1992; 1: 275.

108. Gavin HP, Hanson R, Filisko F. Electrorheological dampers, part II: Testing and modeling. J Appl Mech. 1996; 1050: 48109. 
109. BF JS, Dyke SJ, Sain MK, Carlson JD. Phenomenological model of a magnetorheological damper. J Eng Mech. 1997; 123: 230-238.

110. Yang G, Spencer Jr BF, Carlson JD, Sain MK. Large-scale MR fluid dampers: Modeling and dynamic performance considerations. Eng Struct. 2002; 24: 309-323.

111. Aly AM, Zasso A, Resta F. On the dynamics of a very slender building under winds: Response reduction using MR dampers with lever mechanism. Struct Des Tall Spec Build. 2011; 20: 539-551.

112. Inaudi JA. Performance of variable-damping systems: Theoretical analysis and simulation. Proceedings of the 3rd International Workshop on Structural Control; 2020 July 6th- 8th; Paris, France. London: World Scientific.

113. Fang JQ, Li QS, Jeary AP. Modified independent modal space control of m.d.o.f. systems. J Sound vib. 2003; 261: 421-441.

114. Yang JN, Li Z, Liu SC. Instantaneous optimal control with velocity and acceleration feedbacks. J Probabilistic Eng Mech. 1991; 16: 204-221.

115. Li QS, Liu DK, Fang JQ. Optimum design of actively controlled structures using genetic algorithms. Adv Struct Eng. 1999; 2: 109-118.

116. Karnopp D, Crosby MJ, Harwood RA. Vibration control using semi-active force generators. J Eng Ind. 1974; 96: 619-626.

117. Leitmann G. Semiactive control for vibration attenuation. J Intell Mater Syst Struct. 1994; 5: 841846.

118. Inaudi JA. Modulated homogeneous friction: A semi-active damping strategy. Earthq Eng Struct Dyn. 1997; 26: 361-376.

119. Dyke SJ, Spencer BF. A comparison of semi-active control strategies for the MR damper. Proceedings of the International Conference on Intelligent Information Systems (IIS 97); 1997 December 8th10th; Grand Bahama Island, Bahamas. Piscataway: Institute of Electrical and Electronics Engineer.

120. Jansen LM, Dyke SJ. Semiactive control strategies for MR dampers: Comparative study. J Eng Mech. 2000; 126: 795-803.

121. Feng MQ, Mita A. Vibration control of tall buildings using mega subconfiguration. J Eng Mech. 1995; 121: 1082-1088.

122. Chang CC, Qu WL. Unified dynamic absorber design formulas for wind-induced vibration control of tall buildings. Struct Des Tall Build. 1998; 7: 147-166.

123. Min KW, Kim J, Lee HR. A design procedure of two-way liquid dampers for attenuation of windinduced responses of tall buildings. J Wind Eng Ind Aerodyn. 2014; 129: 22-30.

124. Pirner M, Urushadze S. Liquid damper for suppressing horizontal and vertical motions- parametric study. J Wind Eng Ind Aerodyn. 2007; 95: 1329-1349.

125. Aly AM, Christenson RE. On the evaluation of the efficacy of a smart damper: A new equivalent energy-based probabilistic approach. Smart Mater Struct. 2008; 17: 045008.

126. Rezaee M, Aly AM. Proposed theory of semiactive gains for smart dampers in MDOF systems. J Struct Eng. 2019; 145: 04019155.

127. Aly AM. Control of wind-induced motion in high-rise buildings with hybrid TM/MR dampers. Wind Struct. 2015; 21: 565-595. 


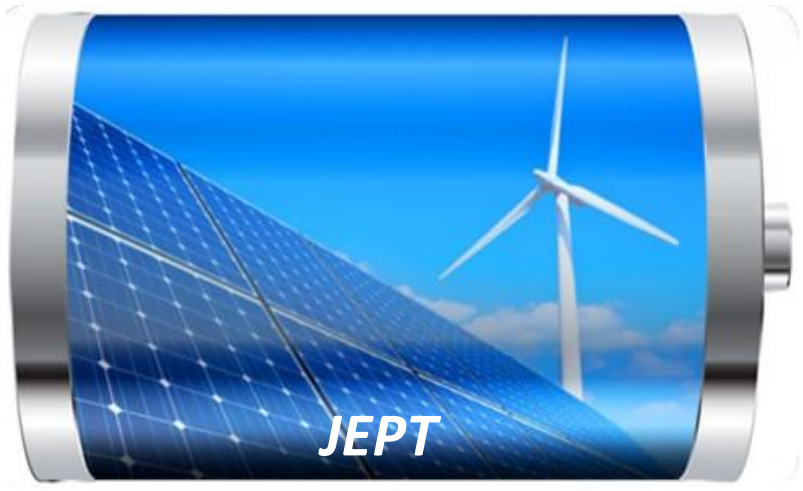

Enjoy JEPT by:

1. Submitting a manuscript

2. Joining in volunteer reviewer bank

3. Joining Editorial Board

4. Guest editing a special issue

For more details, please visit:

http://www.lidsen.com/journal/jept 